Canadian

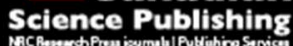

Applied Physiology, Nutrition, and Metabolism Physiologie appliquée, nutrition et métabolisme

\title{
Comparison of immunohematological profile between endurance and power-oriented elite athletes
}

\begin{tabular}{|c|c|}
\hline Journal: & Applied Physiology, Nutrition, and Metabolism \\
\hline Manuscript ID & apnm-2016-0435.R2 \\
\hline Manuscript Type: & Article \\
\hline Date Submitted by the Author: & 19-Oct-2016 \\
\hline Complete List of Authors: & $\begin{array}{l}\text { Morgado, José; Faculty of Human Kinetics - University of Lisbon, } \\
\text { Physiology and Biochemistry of Exercise } \\
\text { Matias, Catarina; Faculty of Human Kinetics - University of Lisbon, Exercise } \\
\text { and Health Laboratory; Faculty of Human Kinetics - University of Lisbon, } \\
\text { Interdisciplinary Center for Human Performance Study (CIPER) } \\
\text { Monteiro, Cristina; Faculty of Human Kinetics - University of Lisbon, } \\
\text { Physiology and Biochemistry of Exercise } \\
\text { Alves, Francisco; Faculty of Human Kinetics - University of Lisbon, } \\
\text { Physiology and Biochemistry of Exercise; Faculty of Human Kinetics - } \\
\text { University of Lisbon, Interdisciplinary Center for Human Performance } \\
\text { Study (CIPER) } \\
\text { Reis, Joana; Faculty of Human Kinetics - University of Lisbon, Physiology } \\
\text { and Biochemistry of Exercise } \\
\text { Santos, Diana; Faculty of Human Kinetics - University of Lisbon, CIPER - } \\
\text { Exercise and Health Laboratory } \\
\text { Silva, Analiza; Faculdade de Motricidade Humana, Universidade Lisboa } \\
\text { Martins, Fátima; Instituto Nacional de Saúde Dr. Ricardo Jorge, Lisboa, , } \\
\text { Infectious Diseases Dept. } \\
\text { Seixas, Maria; National Health Institute Dr. Ricardo Jorge (INSA), Health } \\
\text { Promotion and non-Communicable Disease Prevention } \\
\text { Rocha-Pereira, Petronila; Universidade de Coimbra, Center for } \\
\text { Neuroscience and Cell Biology } \\
\text { Sardinha, Luís; Faculty of Human Kinetics - University of Lisbon, CIPER - } \\
\text { Exercise and Health Laboratory } \\
\text { Laires, Maria; Faculty of Human Kinetics - University of Lisbon, } \\
\text { Interdisciplinary Center for Human Performance Study (CIPER) }\end{array}$ \\
\hline Keyword: & judo, swimming < sports, Immune System, Hematology, Lymphocytes \\
\hline
\end{tabular}

\section{SCHOLARONE \\ Manuscripts}


1 Title: Comparison of immunohematological profile between endurance and power-oriented elite 2 athletes

3

4 Authors: José P. Morgado ${ }^{1}$; Catarina N. Matias ${ }^{1,2^{*}}$, Cristina P. Monteiro ${ }^{1}$, Francisco Alves ${ }^{1}$, Joana F. $5 \quad$ Reis $^{1,3}$, Diana A. Santos ${ }^{2}$, Analiza M. Silva ${ }^{2}$, Fátima Martins ${ }^{4}$, Maria T. Seixas ${ }^{5}$, Petronila Rocha-

6 Pereira $^{6}$, Luís B. Sardinha ${ }^{2}$, Maria J. Laires ${ }^{1}$

\section{Affiliations:}

91 - Physiology and Biochemistry of Exercise Laboratory, CIPER, Faculdade de Motricidade Humana, 10 Universidade Lisboa, Portugal;

112 - Exercise and Health Laboratory, CIPER, Faculdade de Motricidade Humana, Universidade Lisboa, 12 Portugal;

133 - Universidade Europeia, Lisboa, Portugal;

144 - Infectious Diseases Dept., Instituto Nacional de Saúde Dr. Ricardo Jorge, Lisboa, Portugal;

155 - Health Promotion and Chronicle Diseases Dept., Instituto Nacional de Saúde Dr. Ricardo Jorge, 16 Lisboa, Portugal;

176 - Center for Neuroscience and Cell Biology, Universidade de Coimbra, Coimbra, Portugal.

\section{Corresponding Author: Catarina N. Matias ${ }^{1,2}$}

Physiology and Biochemistry of Exercise Laboratory, CIPER, Faculdade Motricidade Humana,

21 Universidade de Lisboa, Estrada da Costa, 1499-688 Cruz-Quebrada, Portugal

22 Phone: +351 214149 174; Fax: (351) 2141491 93. Email: cmatias@fmh.ulisboa.pt 


\section{Authors' Adresses:}

José Pedro Morgado ${ }^{1}$ - Faculdade de Motricidade Humana, Universidade de Lisboa, Laboratório de Fisiologia e Bioquímica do Exercício, Estrada da Costa 1499-002, Cruz-Quebrada, Portugal, Email: morgado.ze@gmail.com

Cristina Paula Monteiro ${ }^{1}$ - Faculdade de Motricidade Humana, Universidade de Lisboa, Laboratório de Fisiologia e Bioquímica do Exercício, Estrada da Costa 1499-002, Cruz-Quebrada, Portugal, Email: cmonteiro@fmh.ulisboa.pt

Francisco Alves ${ }^{1}$ - Faculdade de Motricidade Humana, Universidade de Lisboa, Laboratório de Fisiologia e Bioquímica do Exercício, Estrada da Costa 1499-002, Cruz-Quebrada, Portugal, Email: falves@fmh.ulisboa.pt

Joana Filipa Reis ${ }^{1,3}$ - Faculdade de Motricidade Humana, Universidade de Lisboa, Laboratório de Fisiologia e Bioquímica do Exercício, Estrada da Costa 1499-002, Cruz-Quebrada, Portugal, Email: joanareis30@gmail.com

Diana A. Santos ${ }^{2}$ - Faculdade de Motricidade Humana, Universidade de Lisboa, Laboratório de Exercício e Saúde, Estrada da Costa 1499-002, Cruz-Quebrada, Portugal, Email: dianasantos@fmh.ulisboa.pt Analiza M. Silva ${ }^{2}$ - Faculdade de Motricidade Humana, Universidade de Lisboa, Laboratório de Exercício e Saúde, Estrada da Costa 1499-002, Cruz-Quebrada, Portugal, Email: analiza@fmh.ulisboa.pt

Fátima Martins ${ }^{4}$ - Instituto Nacional de Saúde Doutor Ricardo Jorge, IP, Departamento de Doenças Infecciosas, Avenida Padre Cruz, 1649-016 Lisboa, Portugal, Email: fatima.martins@ insa.min-saude.pt Maria Teresa Seixas ${ }^{5}$ - Instituto Nacional de Saúde Doutor Ricardo Jorge, IP, Departamento de Promoção da Saúde e Prevenção de Doenças Não Transmissíveis, Avenida Padre Cruz, 1649-016 Lisboa, Portugal, Email: teresa.seixas@insa.min-saude.pt 
48 Luis Sardinha ${ }^{2}$ - Faculdade de Motricidade Humana, Universidade de Lisboa, Laboratório de

49 Exercício e Saúde, Estrada da Costa 1499-002, Cruz-Quebrada, Portugal, Email:

50 lsardinha@fmh.ulisboa.pt

51 Petronila Rocha-Pereira ${ }^{6}$ - Centro de Neurociências e Biologia Celular, Universidade de Coimbra,

52 Rua Larga, Faculdade de Medicina, Pólo I, $1^{\circ}$ andar, 3004-504 Coimbra, Portugal

53 Maria José Laires ${ }^{1}$ - Faculdade de Motricidade Humana, Universidade de Lisboa, Laboratório de

54 Fisiologia e Bioquímica do Exercício, Estrada da Costa 1499-002, Cruz-Quebrada, Portugal, Email:

55 mjlaires@fmh.ulisboa.pt

56

57 
Abstract

59

There is general perception that elite athletes are highly susceptible to changes in immunohematological

60 profile.

61 Purpose: to compare immunohematological parameters of elite athletes of different aerobic and 62 muscular strength sports and analyze changes over 2-months.

63 Methods: 16 judoists and 14 swimmers were evaluated 2-months before (M1) and prior to competition 64 (M2). Hemogram and lymphocytes subpopulations were assessed with automatic counter and flow 65 cytometry, respectively.

66 Results: judoists had higher neutrophils, and lower monocytes and eosinophils percentages than 67 swimmers at M1 and M2. At M2 judoists had lower red blood cells (RBC), hemoglobin, and hematocrit than swimmers. At M2 judoists' hematocrit, and CD16 decreased while swimmers' hemoglobin and hematocrit increased.

Conclusions: neither sports characteristics nor intense training seem to displace the athletes'

71 immunohematological profile out of the clinical range, despite the possibility of occurrence of 72 microlesions that may stimulate production of leukocytes and reduction of RBC in judoists.

73

74 Keywords: Judo; Swimming; Training; Immune System; Hematology, Red blood cells, White blood 75 cells, Lymphocytes. 


\section{Introduction}

There is a general perception that elite athletes are more susceptible to suffer from changes in immunohematological profile with possible health consequences due to high intensity training sessions. However, to date, the associations between intense exercise and health problems have not been conclusive. Prolonged intense exercise sessions may induce "hemodilution and/or immunesupression"; nevertheless, these situations have been shown to be reversible with adequate periods of rest (Gleeson 2006). Some reports of infections and anemias in exercising population tend to favour a higher incidence of health problems among athletes, if compared to sedentary or moderately exercising individuals (Shaskey and Green 2000; Malm 2004; Mercer and Densmore 2005; Gleeson 2006; Banfi et al. 2011; Rama et al. 2013). Health problems may affect athletes differently as a consequence of specific sports characteristics such as: intensity, frequency and duration of the task, the quality and duration of the resting periods between training sessions, the phase of training program during the period under investigation, as well as environmental factors (Schumacher et al. 2002; Malm 2004). Stability of immune and hematological parameters over long-lasting periods is crucial for athletes in order to maintain optimal performance (Malm 2004; Mercer and Densmore 2005; Gleeson 2006). Nevertheless, none of the aforementioned investigations focused on the effects of an endurance or a power-oriented sport on the immune and hematological variables. In fact, most common findings refer mainly the hematological differences in athletes when comparing with non-athletes. Some authors have found that athletes have higher white blood cells (WBC), decreased red blood cells (RBC), hemoglobin (Hb), and hematocrit $(\mathrm{Ht})$ levels or a dilutional pseudoanemia, caused by plasma volume (PV) expansion (Shaskey and Green 2000; Schumacher et al. 2002; Banfi et al. 2006; Morkeberg et al. 2009; Banfi et al. 2011; Broadbent 2011), while others have observed no differences between athletes and non-athletes or lower WBC in athletes (Banfi et al. 2006; Saygin et al. 2006). In endurance cyclists, Corsetti and colleagues (2012) reported (data also supported by Mørkeberg et al. (2009) but contrary to data from Saris et al.(1998)) a decrease of $\mathrm{Hb}$ values during the first part of a stage race (until day 12 out of 22). Authors 
103 inferred that the decrease in $\mathrm{Hb}$ and, consequently, in $\mathrm{Ht}$ and $\mathrm{RBC}$, were expected and assigned the

104 phenomenon to hemodilution typical of heavy exercise, as there was an increase of $1.6 \%$ in PV during

105 this first phase. In the second part of the race (from day 12 to day 22), these authors verified that $\mathrm{Hb}$

106 stabilised and PV \% changes showed modest increases. Anemia as a result of decreased RBC, $\mathrm{Hb}$, and

107 Ht has proved to have negative effects on physical exercise performance (Schumacher et al. 2002),

108 while dilutional pseudoanemia is not considered a pathological state and normalises with training

109 cessation after a short period of time (3 to 5 days) (Shaskey and Green 2000; Mercer and Densmore

110 2005). Corsetti and colleagues (2012) reinforce that the time course of $\mathrm{Hb}$ decrease should also be

111 established, since some authors observed a decrease as soon as after 2 or 3 days (Hue et al. 2006;

112 Schumacher et al. 2008; Garvican et al. 2010) while, for others it was not yet evident after 4 days

113 (Konig et al. 2003).

114 It has been demonstrated that immune and hematological variables are highly sensitive to exercise and

115 could display seasonal adaptations, depending on training programs and competition schedule of the

116 athletes (Gleeson et al. 1999; Schumacher et al. 2002; Banfi et al. 2006; Morkeberg et al. 2009; Banfi et

117 al. 2011; Broadbent 2011). Data comparing these variables in different sports as well as within different

118 training intensities and levels of performance are scarce and inconclusive.

119 Considering that swimming is an endurance and predominantly aerobic sport characterized by low

120 impact and that judo is a predominant power and strength sport with a high level of physical impact

121 where injuries and traumas are frequent and sometimes serious, this study aim was to compare immune

122 and hematological parameters of elite athletes of two sports with different aerobic and muscular strength

123 characteristics (endurance - swimming / power - judo) and analyze the changes occurring over a 2-

124 month training period.

125

126 Materials and methods

127 


\section{Participants}

129 Thirty elite Portuguese male athletes comprising 16 judoists and 14 swimmers were recruited for the

130 study. Top-level judo athletes were recruited from the Lisbon region with the help of the Portuguese

131 judo federation, and swimmers were recruited from the three most representative swimming teams of

132 the Lisbon region.

133 All judoists were national medallists, several were international medallists, and some participated in

134 European and/or World Championships or in the Olympic Games.

135 All swimmers were medallists at the national level and several participated in the European and/or

136 World Championships.

137 After receiving detailed information about the aim of the study and the possible risks of the 138 investigation, either the subjects or their parents, as appropriate, provided their written informed consent

139 to participate. All procedures were approved by the Ethic Committee of the Faculty of Human Kinetics, 140 University of Lisbon and were conducted in accordance with the declaration of Helsinki for human 141 studies (World Medical Association 2008).

142

143 Study design

144 This study used a longitudinal approach: the baseline testing (M1) and the competitive-period 145 assessment (M2) that occurred approximately two months apart. Baseline period (M1) corresponds to 146 middle september and october, while M2 corresponds to November/December, dependending on the 147 baseline assessment and also depending on judo individual competions or swimming competitions.

148 Judoists training included $\sim 2 \mathrm{~h}$ in the morning and $\sim 2 \mathrm{~h}$ in the evening, 6 days a week. From those, 149 twice a week the morning sessions aimed to improve cardiorespiratory fitness and strength while the 150 other sessions consisted of judo specific skills, drills and randori (fighting practice). 
151 Swimmers undertook $\sim 13-15 \mathrm{~h}$ of pool training and $\sim 4 \mathrm{~h}$ of dry-land training per week. Swimming

152 training macrocycle was characterized by an aerobic training predominance with the progressive

153 increase of training volumes and intensities from M1 to M2 period assessment.

154 At each moment of evaluation, all measurements were performed on the same day after a 12-hour fast,

155 with no alcohol or stimulant beverage consumption or exercise participation taking place within the last

15615 hours. During the period of observation athletes were asked not to take dietary supplements, nor any

157 kind of medication other than that prescribed for episodes of acute illness.

158

159

160

161

162

163

164

165

166

167

168

169

170

171

172

173

174

175

\section{Anthropometric Measures}

Height $(\mathrm{cm})$ and body weight $(\mathrm{kg})$ were assessed to the nearest $0.1 \mathrm{~cm}$ and $0.01 \mathrm{~kg}$ respectively (SECA Scale and Stadiometer, Hamburg-Germany), and body mass index (BMI; $\mathrm{kg} \cdot \mathrm{m}^{-2}$ ) was calculated.

\section{Immune and hematological parameters}

Blood samples were collected by venipuncture from the antecubital vein into tubes containing EDTA and analyzed in the next hour.

Hemogram quantification

Whole blood was analyzed in an automatic cell counter (Coulter LH 750 Beckman) for total white blood cells (WBC), neutrophils, monocytes, lymphocytes, eosinophils and basophils, red blood cells (RBC), hemoglobin $(\mathrm{Hb})$ and hematocrit $(\mathrm{Ht})$ quantification.

Lymphocytes assessment

Total lymphocytes and subsets CD3 (total T cells), CD4 (T helper), CD8 (T cytotoxic), CD16 56 (NK cells) and CD19 (B cells) were counted by flow cytometry, using the FACS Calibur Becton, Dickinson and Company (Biosciences 2000) cytometer equipped with two laser beams at 635 e $488 \mathrm{~nm}$. This cytometer was linked to a Macintosh computer that uses the software Multiset to analyse the 
176 cytometry results, according to standard procedures (Burtis and Ashwood 1999; Radbruch 2000;

177 Goldsby et al. 2003).

178

\section{Statistical analysis}

180 Descriptive statistics was applied to characterize the sample. All variables were checked for normality

181 using Shapiro-Wilk test.

182 One sample t-test was used to compare group means with the upper or lower limits of the reference

183 interval provided by the National Health Institute Doctor Ricardo Jorge (INSA) (Lewis et al. 2006) to

184 verify if participants were within the "clinically normal" values associated with each variable.

185 Repeated measures ANOVA was used for the assessment of specific sports characteristics: aerobic and 186 strength (between-subjects factor - Swimmers vs. Judoists) and training (within-subjects factor - M1 vs.

187 M2) on the parameters of interest. Sphericity assumptions were evaluated with the Mauchly's test. If the 188 assumptions of the ANOVA for repeated measures were not met, or of if there was a significant 189 interaction between the specific sports characteristics and training effects, analysis of the effect of 190 training were performed in each group separately by paired sample T-test (or Wilcoxon test when 191 normality was not observed) and differences between groups were assessed using independent samples

192 T-test for parametric variables (or Mann-Whitney test when a non-normal distribution was observed).

193 Data were analyzed with PASW for Windows version 21.0 (SPSS Inc., an IBM Company, Chicago).

194 For all tests, statistical significance was set at $\mathrm{p}<0.05$.

195

\section{Results}

197 Participants' characteristics, immune and hematological parameters of elite judoists and swimmers are

198 displayed in Table 1 for M1 and M2. BMI was higher in judoists than in swimmers.

199 At both moments, all parameters were within the clinical reference interval associated with each 200 variable. 
Judoists showed a higher percentage of neutrophils $(\mathrm{F}=11.550 ; \mathrm{p}=0.002)$, and lower percentages of monocytes $(\mathrm{F}=24.293 ; \mathrm{p}<0.001)$ and eosinophils $(\mathrm{F}=5.866 ; \mathrm{p}=0.022)$ than swimmers at both moments of evaluation. At the competitive period judoists presented lower values of $\mathrm{RBC}(\mathrm{p}=0.025), \mathrm{Hb}(\mathrm{p}=0.021)$, and $\mathrm{Ht}(\mathrm{p}<0.001)$.

The competitive period significantly differed from baseline, Ht $(\mathrm{p}<0.001)$ and CD16 lymphocytes count $(p=0.029)$ decreased in judoists while $\mathrm{RBC}(\mathrm{p}<0.001), \mathrm{Hb}(\mathrm{p}=0.003)$, and $\mathrm{Ht}(\mathrm{p}=0.006)$ increased in swimmers.

\section{Discussion}

Studies addressing the question how exercise affects immune and hematological parameters regarding different sports disciplines are scarce (Horn et al. 2010). Few studies were conducted regarding only swimmers (Morgado et al. 2012; Rama et al. 2013) and judoists (Yamamoto et al. 2008; Shimizu et al. 2011; Garatachea et al. 2012), nevertheless, to our knowledge, our study is the first concerning judoists and swimmers.

We wish to remark that all immune and hematological mean values were within the normal clinical reference range. Thus, our results do not support the common idea that elite athletes are more prone to infectious diseases or anemia (Malm 2004; Gleeson 2006).

Regarding sports disciplines, our results showed no differences in total white blood cells counts (WBC) between judoists and swimmers. However, judoists presented higher percentages of neutrophils and lower percentages of monocytes and eosinophils at both moments of evaluation. Additionally, judoists showed lower RBC counts, $\mathrm{Hb}$, and $\mathrm{Ht}$, at the competitive period, than swimmers.

Low neutrophil counts (neutropenia) seem to occur commonly among athletes (Miura et al. 2005; Horn et al. 2010). It has been shown that more aerobically oriented sports tend to have lower WBC and 
226 neutrophil counts (Horn et al. 2010), which is in accordance with the observed results in our study. The 227 reasons for the aerobic exercise-induced low neutrophil counts are unclear (Barreda et al. 2004; Horn et 228 al. 2010). The mechanisms involved in this line of defense against invading microorganisms result in the 229 death of both the microorganism and the neutrophil (Miura et al. 2005; Segel et al. 2011). This cell loss 230 is compensated for by the ability to produce neutrophils at a prodigious rate and to have them 231 accumulate in the tissues (Segel et al. 2011). Although neutrophils are an important cell population in 232 the innate defense system, they have a dichotomous role as both perpetrator of tissue damage and 233 initiator of repair. Neutrophils infiltrate injured tissues but can also be present after no injurious exercise 234 (Butterfield et al. 2006). These cells have both specific and nonspecific defensive immune system 235 functions that can cause tissue damage in isolation or as sequela to another tissue injury. It might seem 236 that limiting the action of neutrophils would be clinically beneficial, but these cells are also responsible 237 for initiating the reparative process that is later managed by monocytes and macrophages (Butterfield et 238 al. 2006).

239 Our results show higher mean percentage of neutrophils and lower mean percentage of monocytes in 240 judoists. This may be a consequence of the high impact strength training of these athletes, frequently 241 involving contusions that may result into microlesions in the muscular tissue. In theory, these 242 microlesions may stimulate the production of neutrophils from the bone marrow and simultaneously the 243 migration of monocytes into the damaged tissue differentiating into macrophages in order to phagocyte 244 damaged cells, as suggested above.

245 Higher mean percentage of eosinophils in swimmers may suggest a higher prevalence of allergies, 246 possibly due to the environmental conditions in the pool facilities.

247 In an epidemiological study that investigated the RBC characteristics and iron metabolism in athletes at 248 different levels of performance and in distinct sports, it was concluded that the specific type of exercise 249 plays a major role in the hematological response, and that there are differences between endurance250 trained athletes and athletes engaging strength training for RBC, Hb, and Ht (Schumacher et al. 2002). 
251 In the aforementioned investigation neither judo nor swimmers were included in the sample, but 252 categories were created based on sports type in, namely, endurance and power categories. Schumacher 253 and colleagues (2002) reported lower values of these parameters for endurance training athletes 254 (cycling, running, or other endurance sports), when compared to strength athletes (weight lifting, shot255 put, hammer-throwing, javelin, wrestling or discus). Our data showed different results from this study, 256 as our power-oriented athletes (judoists) presented lower values than endurance training athletes 257 (swimmers) for RBC counts, $\mathrm{Hb}$, and $\mathrm{Ht}$ at the competitive period. These divergent results may have 258 occurred due to the fact that the sports performed by the strength-training group studied by these authors 259 were mostly sports with low impact.

260 The investigation conducted by Corsetti and colleagues (2012) reinforce the need for hematological 261 monitoring of athletes, especially in endurance sports, as it is important because of the occurrence of 262 "sports anemia". Although this may be a direct consequence of the hemodilution, linked to heavy 263 physical exercise, other additional sources have been recognized. Among them, hemolysis is the most 264 frequent, due to an important destruction of RBCs resulting from the impact with hard surfaces such as 265 the ground (foot-strike hemolysis) or to their mechanical breakdown in contracting muscles.

266 We propose that the results obtained for $\mathrm{RBC}$ and $\mathrm{Ht}$ corroborate the suggestion anticipated for the 267 results observed for neutrophils and monocytes, reinforcing the possible occurrence of microlesions 268 with some intravascular hemolysis, as it has previously been suggested (Malczewska et al. 2000; Matias 269 et al. 2008). Also, it has been proposed free Hb capture by Hp and removal of the Hp-Hb complex from 270 circulation as cause of the low values of $\mathrm{Hp}$ observed in an investigation conducted in judoists (Matias 271 et al. 2008) and in studies including runners (Schumacher et al. 2002) and cyclists (Corsetti et al. 2012). 272 As $\mathrm{Hp}$ is an acute phase protein, its concentration increases with inflammation. One other possible 273 mechanism to explain $\mathrm{RBC}$ and $\mathrm{Hb}$ decreases is the increase in the production of reactive oxygen and 274 nitrogen species that occur during exercise. These species can attack RBCs, in particular their 275 membranes, compromising their flexibility and functionality. Without mechanical stressors, these 
276 senescent cells are mostly removed intact by the spleen and do not lyse or fragment in the general 277 circulation, at least to any significant extent (Jollow and McMillan 2001). However, their increased 278 removal from circulation can also contribute to the reduction of RBCs and $\mathrm{Hb}$ although this would not 279 induce hypohaptoglobinemia.

280 Nevertheless Haptoglobin (Hp), other acute phase proteins, or other inflammatory or oxidation markers 281 were not scrutinized in the present investigation.

282 A seasonal follow-up of the immunohematological response is essential for elite athletes in order to 283 avoid or limit performance pitfalls. Our results show that at the competitive period, $\mathrm{RBC}, \mathrm{Hb}$ and $\mathrm{Ht}$ 284 increased in swimmers while RBC, Ht, and CD16 lymphocytes count decreased in judoists. Numerous 285 studies demonstrated that immune and hematological variables are highly sensitive to the effects of 286 exercise and can display seasonal adaptations, depending on training and competition schedule of the 287 athletes (Gleeson et al. 1999; Schumacher et al. 2002; Banfi et al. 2006; Morkeberg et al. 2009; Banfi et al. 2011; Broadbent 2011). Literature regarding the variations of the immunohematological parameters along the training seasons is quite controversial. Our result showed that total WBC were highly stable in

both sports during the period of investigation suggesting the nonappearance of viral and/or bacterial 291 diseases (Schumacher et al. 2008). This is in accordance with the reports that intensive training during 292 long-lasting periods does not cause significant modifications on immune parameters (Banfi et al. 2006; Ostojic and Ahmetovic 2009; Garatachea et al. 2012; Morgado et al. 2012). In swimmers, Morgado et al (2012) reported that the frequency and absolute numbers of the different cell populations in the blood did not significantly change during a season of training, with the exception of a decrease in the absolute numbers of monocytes in the first 7 weeks. Similar results were observed in judoists by Garatachea et al. 297 (2012) who stated that the leukocyte profile did not change over a 7-week period of weight loss, with 298 the exception of monocytes that increased from week 3 to week 7.

299 Regarding lymphocytes subpopulations, Shimizu and colleagues (2011) reported a decrease in 300 lymphocytes CD3, CD4, and CD8, in judoists. In judoists from our study, a decreased in CD16 was 
301 observed during the period of investigation. Similar results were observed by Rama and colleagues

302 (2013) in swimmers, where CD16 cells decreased from a baseline to a period coincident with an 303 increased training load period. These cells are considered unspecific defenses, as they act without 304 sensitization against infection (Gleeson 2006). Changes of immune cells counts may reflect adaptation 305 to the metabolic and mechanical stressors evident in sports (Pyne 1994), rather than an underlying 306 pathological response and have been reported before in several sports, especially at periods of high 307 training volume (Degoutte et al. 2006; Yamamoto et al. 2008; Shimizu et al. 2011; Garatachea et al. 308 2012; Morgado et al. 2012; Rama et al. 2013). As in other studies, this decrease in CD16 may be an 309 indication that the innate immune system may be more susceptible to periods of great physical demand 310 than the adaptive immune system.

311 Regarding RBC system, the true prevalence of anemia in athletic populations remains unknown 312 (Shaskey and Green 2000; Mercer and Densmore 2005), however, it is currently accepted that 313 alterations of the RBC system truly influence physical performance (Schumacher et al. 2002). Literature 314 reviews indicated that numerous studies have examined the prevalence of "anemia" in athletic 315 populations (Shaskey and Green 2000; Mercer and Densmore 2005). Authors suggested that possibly 316 anemia does not occur, but instead a "dilutional pseudoanemia" seems to be the response to exercise. 317 Dilutional pseudoanemia can be easily explained in elite athletes as it is a benign temporary condition 318 that is developed secondary to training-induced plasma expansion and hemodilution (Shaskey and 319 Green 2000; Mercer and Densmore 2005). This condition is very different from sports anemia, that 320 results as a pathologic cause of RBC deficiency in athletes, intravascular hemolysis and iron deficiency 321 (Mercer and Densmore 2005). Thus, $\mathrm{Hb}$ and $\mathrm{Ht}$ have been pointed out as poor indicators of the RBC 322 system in athletes as they are easily influenced by exercise (Schumacher et al. 2002). However, 323 nutritional anemia probably occurs more frequently in athletes than the so-called "dilutional 324 pseudoanemia", specifically in judoists or other sports where body weight restriction is placed at a 325 premium (Shaskey and Green 2000). 
326 In our swimmers, mean values of $\mathrm{RBC}, \mathrm{Hb}$ and $\mathrm{Ht}$ increased at the competitive period, possibly 327 associated with an improvement in endurance performance, as described elsewhere (Schumacher et al. 328 2002), while in judoists Ht decreased reinforcing the already proposed possibility of occurrence of 329 microlesions with intravascular hemolysis.

330 Despite the clinical normal values observed in all parameters, it would be interesting to reinforce that 331 swimmers engage a taper period prior to competition while judoists frequently undergo weight 332 reduction. This weight reduction can be achieved due to intracellular water decrease, which has been 333 proven to be related to an increase in the cell membrane fragility (Matias et al. 2015). Taper periods aim 334 to promote recovery of fatigue indicators and to allow the athlete to compete at their best.

335 In this study we observed higher levels of neutrophils in judoists than in swimmers and lower levels of 336 hematological parameters at M2, suggesting some exercise-induced trauma in judoists. For this reason, 337 caretakers of athletes enrolled in judo or other sports with high and repeated body contact and impact, 338 should carefully monitor iron metabolism. In addition, at M2 not only hematological parameters had 339 decreased in judoists but also CD16 cells, suggesting a decrease of the innate immune response. As all 340 the values are within the reference limits established for the general population, discipline-adapted 341 immunohematological reference values are improbable to arise. Thus, individual profiles should be 342 established in order to allow the identification of increased susceptibility periods and avoid or limit 343 performance pitfalls or the development of illness.

344 We reinforce the need to adopt preventive strategies in order to avoid the onset of fatigue or health 345 issues that might compromise attendance to training sessions or health, especially during periods of 346 heavy training loads.

347 In conclusion, our results suggest that neither sports discipline with these particular characteristics 348 (endurance $v s$ power) nor intense training, from a baseline to a competitive period, seem to affect the 349 immunohematological profile of elite swimmers or judoists. Nevertheless, sports with a higher contact, 350 such as judo, can involve the occurrence of microlesions that may stimulate the physiological 
351 production of neutrophils, the migration of monocytes into the damaged tissue and the reduction of 352 RBCs.

353 As all variables remained within the clinically normal range during the period of investigation, further 354 research should be performed in order to achieve a better and comprehensive knowledge about the 355 implications of long-lasting training periods of sports with the prevalence of endurance or power 356 characteristics on the immunohematological profile of athletes.

\section{Conflict of interest statement}

359 The authors have no conflicts of interest to declare.

\section{Acknowledgements}

362 We would like to express our gratitude to the athletes for their time and effort. José P. Morgado and 363 Catarina N. Matias were supported by the Portuguese Foundation for Science and Technology 364 (SFRH/BD/ 48211/2008 and SFRH/BD/61520/2009, respectively).

\section{References}

367 Banfi, G., Del Fabbro, M., Mauri, C., Corsi, M.M., and Melegati, G. 2006. Haematological parameters 368 in elite rugby players during a competitive season. Clin Lab Haematol 28(3): 183-8. doi: CLH77110.1111/j.1365-2257.2006.00771.x. PMID: 16706935.

Banfi, G., Lundby, C., Robach, P., and Lippi, G. 2011. Seasonal variations of haematological parameters in athletes. Eur J Appl Physiol 111(1): 9-16. doi: 10.1007/s00421-010-1641-1. PMID: 20842374.

Barreda, D.R., Hanington, P.C., and Belosevic, M. 2004. Regulation of myeloid development and 374 function by colony stimulating factors. Dev Comp Immunol 28(5): 509-54. doi: 10.1016/j.dci.2003.09.010. PMID: 15062647. 
Biosciences, B. 2000. Introduction to Flow Cytometry: A Learning Guide. San Jose, CA: Becton, Dickinson and Company.

Broadbent, S. 2011. Seasonal changes in haematology, lymphocyte transferrin receptors and intracellular iron in Ironman triathletes and untrained men. Eur J Appl Physiol 111(1): 93-100. doi: 10.1007/s00421-010-1635-z. PMID: 20821024.

Burtis, C. and Ashwood, E. 1999. Tietz TextBook of Clinical Chemistry: W.B.Saunders Company.

Butterfield, T.A., Best, T.M., and Merrick, M.A. 2006. The dual roles of neutrophils and macrophages in inflammation: a critical balance between tissue damage and repair. J Athl Train 41(4): 457-65. doi. PMID: 17273473.

Corsetti, R., Lombardi, G., Lanteri, P., Colombini, A., Graziani, R., and Banfi, G. 2012. Haematological and iron metabolism parameters in professional cyclists during the Giro d'Italia 3-weeks stage race. Clin Chem Lab Med 50(5): 949-56. doi: 10.1515/cclm-2011-0857. PMID: 22628339.

Degoutte, F., Jouanel, P., Begue, R.J., Colombier, M., Lac, G., Pequignot, J.M., and Filaire, E. 2006. Food restriction, performance, biochemical, psychological, and endocrine changes in judo athletes. Int J Sports Med 27(1): 9-18. doi: 10.1055/s-2005-837505. PMID: 16388436.

Garatachea, N., Hernandez-Garcia, R., Villaverde, C., Gonzalez-Gallego, J., and Torres-Luque, G. 2012. Effects of 7-weeks competitive training period on physiological and mental condition of top level judoists. J Sports Med Phys Fitness 52(1): 1-10. doi: R40123367. PMID: 22327080.

Garvican, L.A., Eastwood, A., Martin, D.T., Ross, M.L., Gripper, A., and Gore, C.J. 2010. Stability of hemoglobin mass during a 6-day UCI ProTour cycling race. Clin J Sport Med 20(3): 200-4. doi: 10.1097/JSM.0b013e3181ddcd5b. PMID: 20445361.

Gleeson, M. 2006. Immune function in sports and exercise. Edinburgh: Churchill Livingstone Elsevier. Gleeson, M., McDonald, W.A., Pyne, D.B., Cripps, A.W., Francis, J.L., Fricker, P.A., and Clancy, R.L. 1999. Salivary IgA levels and infection risk in elite swimmers. Med Sci Sports Exerc 31(1): 6773. doi. PMID: 9927012. 
401

402

403

404

405

406

407

408

409

410

411

412

413

414

415

416

417

418

419

420

421

422

423

424

425

Goldsby, R.A., Kindt, T.J., Osborne, B.A., and Kuby, J. 2003. The inflammatory process(Ed.)^(Eds.), Immunology (5th ed.). New York: W.H. Freeman and Company.

Horn, P.L., Pyne, D.B., Hopkins, W.G., and Barnes, C.J. 2010. Lower white blood cell counts in elite athletes training for highly aerobic sports. Eur J Appl Physiol 110(5): 925-32. doi: 10.1007/s00421-010-1573-9. PMID: 20640439.

Hue, O., Voltaire, B., Hertogh, C., and Blonc, S. 2006. Heart rate, thermoregulatory and humoral responses during a 9-day cycle race in a hot and humid climate. Int J Sports Med 27(9): 690-6. doi: 10.1055/s-2005-872919. PMID: 16586332.

INSA- Instituto Nacional de Saude Dr. Ricardo Jorge 2011. Boletim de Analises Clinicas - Valores Referencia Subpopulações Linfocitárias.

Jollow, D.J. and McMillan, D.C. 2001. Oxidative stress, glucose-6-phosphate dehydrogenase and the red cell. Adv Exp Med Biol 500595-605. doi. PMID: 11765001.

Konig, D., Schumacher, Y.O., Heinrich, L., Schmid, A., Berg, A., and Dickhuth, H.H. 2003. Myocardial stress after competitive exercise in professional road cyclists. Med Sci Sports Exerc 35(10): 167983. doi: 10.1249/01.MSS.0000089248.37173.E7. PMID: 14523304.

Lewis, S.M., Bain, B.J., and Bates, I. 2006. Dacie and Lewis Practical Haematology: Churchill Livingstone Elsevier.

Malczewska, J., Blach, W., and Stupnicki, R. 2000. The effects of physical exercise on the concentrations of ferritin and transferrin receptor in plasma of female judoists. Int J Sports Med 21(3): 175-9. doi: 10.1055/s-2000-299. PMID: 10834348.

Malm, C. 2004. Exercise immunology: the current state of man and mouse. Sports Med 34(9): 555-66. doi. PMID: 15294006.

Matias, C., Silva, A.M., Monteiro, C.P., Raposo, M.F., Limão, F., Martins, F., and Laires, M.J. 2008. Immune system in elite combat athletes. Book of Abstracts of the 13th Annual Congress of ECSS: European College of Sport Science. 
426 Matias, C.N., Monteiro, C.P., Santos, D.A., Martins, F., Silva, A.M., Laires, M.J., and Sardinha, L.B. 2015. Magnesium and phase angle: a prognostic tool for monitoring cellular integrity in judo athletes. Magnes Res 28(3): 92-8. doi: 10.1684/mrh.2015.0389. PMID: 26507750.

Mercer, K.W. and Densmore, J.J. 2005. Hematologic disorders in the athlete. Clin Sports Med 24(3): 599-621, ix. doi: 10.1016/j.csm.2005.03.006. PMID: 16004921.

Miura, M., Umeda, T., Nakaji, S., Liu, Q., Tanabe, M., Kojima, A., Yamamoto, Y., and Sugawara, K. 2005. Effect of 6 months' training on the reactive oxygen species production capacity of neutrophils and serum opsonic activity in judoists. Luminescence 20(1): 1-7. doi: 10.1002/bio.777. PMID: 15586397.

Morgado, J.M., Rama, L., Silva, I., de Jesus Inacio, M., Henriques, A., Laranjeira, P., Pedreiro, S., Rosado, F., Alves, F., Gleeson, M., Pais, M.L., Paiva, A., and Teixeira, A.M. 2012. Cytokine production by monocytes, neutrophils, and dendritic cells is hampered by long-term intensive training in elite swimmers. Eur J Appl Physiol 112(2): 471-82. doi: 10.1007/s00421-011-1966-4. PMID: 21584686.

Morkeberg, J.S., Belhage, B., and Damsgaard, R. 2009. Changes in blood values in elite cyclist. Int J Sports Med 30(2): 130-8. doi: 10.1055/s-2008-1038842. PMID: 18773375.

Ostojic, S.M. and Ahmetovic, Z. 2009. Indicators of iron status in elite soccer players during the sports season. Int J Lab Hematol 31(4): 447-52. doi: CLH106410.1111/j.1751-553X.2008.01064.x. PMID: 18384395 .

Pyne, D.B. 1994. Exercise-induced muscle damage and inflammation: a review. Aust J Sci Med Sport 26(3-4): 49-58. doi. PMID: 8665277.

Radbruch, A. 2000. Flow Cytometry and Cell Sorting. New York: Springer.

Rama, L., Teixeira, A.M., Matos, A., Borges, G., Henriques, A., Gleeson, M., Pedreiro, S., Filaire, E., Alves, F., and Paiva, A. 2013. Changes in natural killer cell subpopulations over a winter training 

season in elite swimmers. Eur J Appl Physiol 113(4): 859-68. doi: 10.1007/s00421-012-2490-x. PMID: 22990626.

Saris, W.H., Senden, J.M., and Brouns, F. 1998. What is a normal red-blood cell mass for professional cyclists? Lancet 352(9142): 1758. doi: 10.1016/S0140-6736(05)79832-9. PMID: 9848362.

Saygin, O., Karacabey, K., Ozmerdivenli, R., Zorba, E., Ilhan, F., and Bulut, V. 2006. Effect of chronic exercise on immunoglobin, complement and leukocyte types in volleyball players and athletes. Neuro Endocrinol Lett 27(1-2): 271-6. doi: 271206A12. PMID: 16648800.

Schumacher, Y.O., Pottgiesser, T., Ahlgrim, C., Ruthardt, S., Dickhuth, H.H., and Roecker, K. 2008. Haemoglobin mass in cyclists during stage racing. Int J Sports Med 29(5): 372-8. doi: 10.1055/s2007-965335. PMID: 17614021.

Schumacher, Y.O., Schmid, A., Grathwohl, D., Bultermann, D., and Berg, A. 2002. Hematological indices and iron status in athletes of various sports and performances. Med Sci Sports Exerc 34(5): 869-75. doi. PMID: 11984308.

Segel, G.B., Halterman, M.W., and Lichtman, M.A. 2011. The paradox of the neutrophil's role in tissue injury. J Leukoc Biol 89(3): 359-72. doi: 10.1189/jlb.0910538jlb.0910538. PMID: 21097697.

Shaskey, D.J. and Green, G.A. 2000. Sports haematology. Sports Med 29(1): 27-38. doi. PMID: 10688281.

Shimizu, K., Aizawa, K., Suzuki, N., Masuchi, K., Okada, H., Akimoto, T., Mesaki, N., Kono, I., and Akama, T. 2011. Influences of weight loss on monocytes and T-cell subpopulations in male judo athletes. J Strength Cond Res 25(7): 1943-50. doi: 10.1519/JSC.0b013e3181e4f9c6. PMID: 21499138.

World Medical Association 2008. Declaration of Helsinki - Ethical Principles for Medical Research involving Human Subjects. WMJ 54(4): 122-125. doi. PMID: 11587468. 
473 Yamamoto, Y., Nakaji, S., Umeda, T., Matsuzaka, M., Takahashi, I., Tanabe, M., Danjo, K., Kojima, 474 A., and Oyama, T. 2008. Effects of long-term training on neutrophil function in male university 475 judoists. Br J Sports Med 42(4): 255-9. doi: 10.1136/bjsm.2007.032011. PMID: 18390768.

476 
Table 1. Participant characteristics, immune and hematological parameters

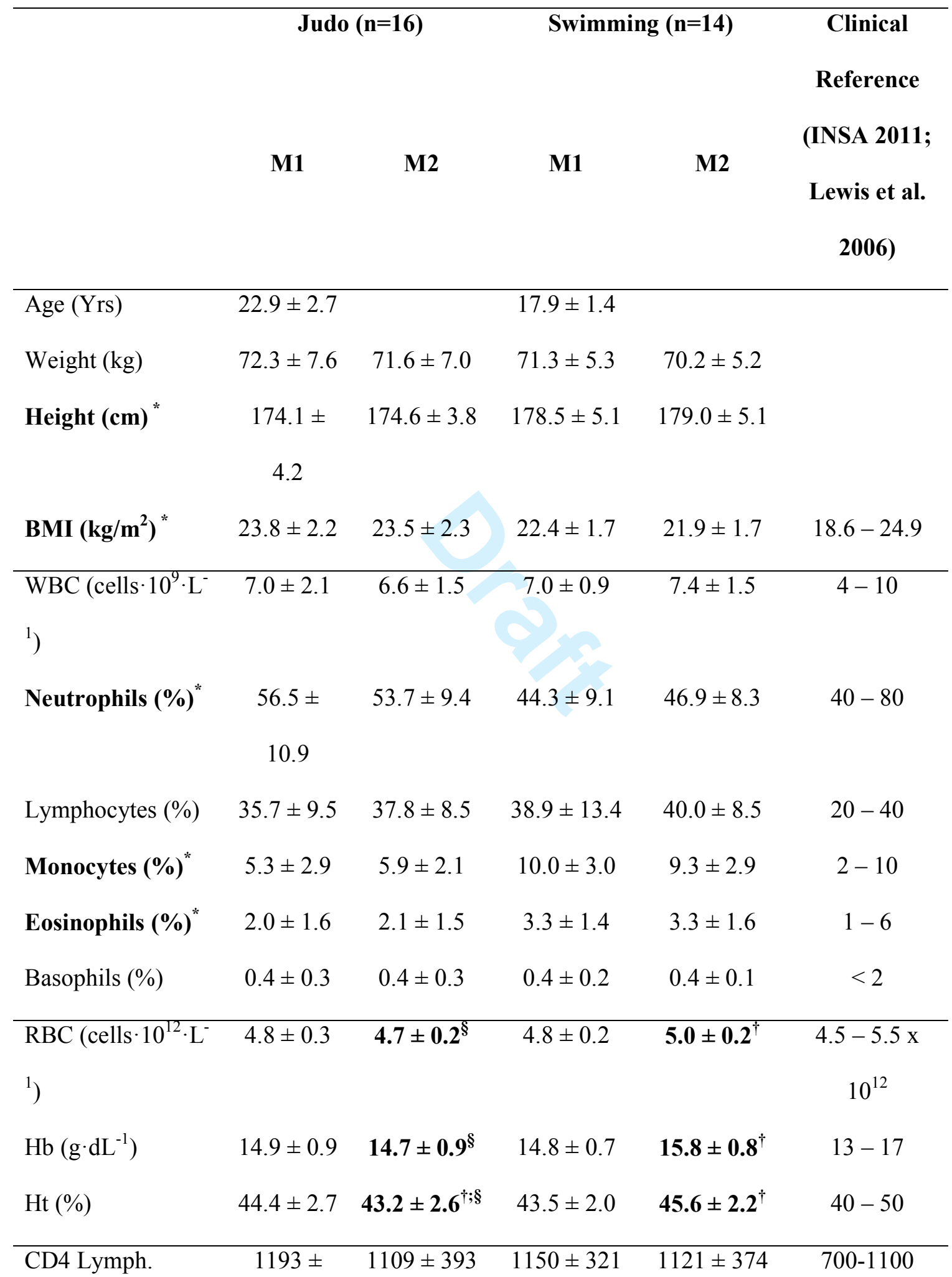




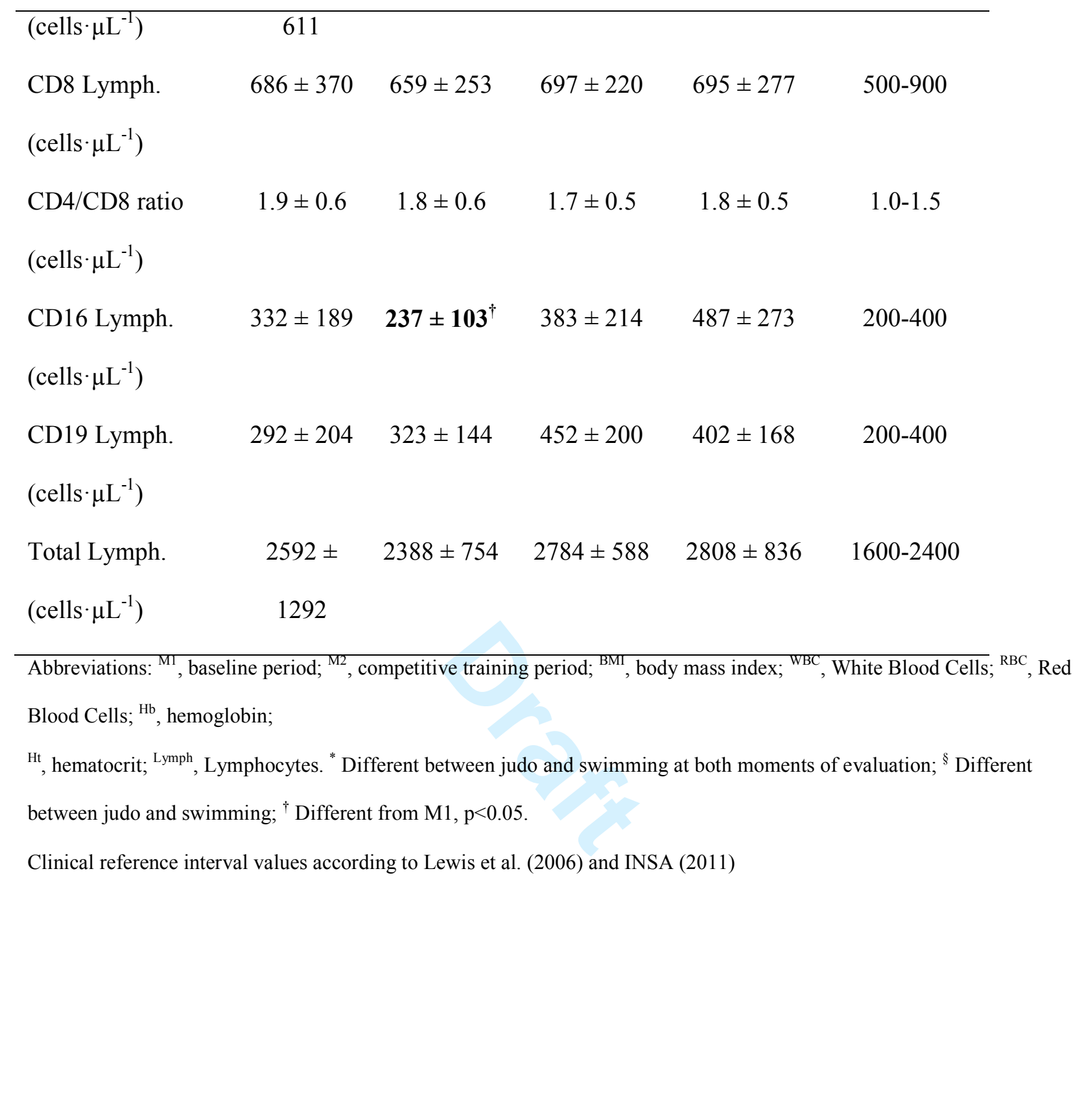

